\title{
Pelatihan Elektronika Dasar Bagi Siswa Sekolah Menengah Atas di Wilayah Kalimantan Barat
}

\author{
Syaifurrahman ${ }^{1)}$, Neilcy Tjahjamooniarsih ${ }^{2}$, Dedy suryadi ${ }^{3}$ \\ Muhammad Saleh ${ }^{4}$, Ade Elbani ${ }^{5)}$ \\ 12)314)5) Teknik ElektroUniversitas Tanjungpura, Pontianak, Indonesia \\ Corresponding Author: Syaifurrahman, syaifurrahman@untan.ac.id
}

\begin{abstract}
Abstrak: Pelatihan elektronika dilaksanakan untuk meningkatkan pengetahuan para siswa pada bidang elektronika untuk meningkatkan minat mereka kuliah di Jurusan Teknik Elektro Universitas Tanjungpura. Terdapat lima sekolah yang menjadi target pelatihan, yaitu MAN IC Sambas, SMKN 1 Sambas, SMAN 1 Siantan, SMAN 1 Paloh Sambas dan SMKN 1 Mandor Landak.Metode yang digunakan adalah diskusi kelas dan praktek dengan melibatkan langsung siswa/i untuk bersama-sama merakit rangkaian elektronika dengan menggunakan modul elektronika yang telah dibuat. Selama kegiatan pelatihan para siswa sangat antusias mengikuti pelatihan yang diberikan hal ini ditunjukkan dengan banyak siswa yang ingin mencoba merangkai rangkaian elektronik dengan modul elektronika yang disediakan. Selanjutnya modul elektronika tersebut diserahkan kepada pihak sekolah agar memberi motivasi kepada siswa untuk mencoba mempelajari rangkaian elektronik lainnya.
\end{abstract}

Kata Kunci: Modul, elektronika, sekolah, pelatihan, siswa

Abstract: This electronics training is carried out to increase the knowledge of students in the field of electronics to increase their interest in studying at the Department of Electrical Engineering,Tanjungpura University. There are five schools targeted for the training, namely: MAN IC Sambas, SMKN 1 Sambas, SMAN 1 Siantan, SMAN 1 Paloh Sambas and SMKN 1 Mandor Landak.The method used is class discussion and practice by directly involving students to jointly assemble electronic circuits using electronic modules that have been made.During the training activities the students were very enthusiastic about participating in the training and this was shown by many students who wanted to try assembling electronic circuits with the provided electronic modules.Furthermore, the electronic modules were handed over to the school in order to motivate students to try to learn other electronic circuits.

Keywords: Module, electronics, school, training, student

\section{Pendahuluan}

Elektronika merupakan bagian dari bidang ilmu teknik elektro (selain, bidang teknik tenaga listrik, teknik telekomunikasi, dan teknik kendali) yang membahas alat listrik arus lemah yang bekerja dengan cara mengendalikan aliran elektron atau partikel bermuatan dari sebuah sumber muatan listrik dalam suatu peralatan elektronik seperti radio, televisi, komputer, peralatan elektronik lainnya. Mempelajari elektronika tidak terlepas dari pengetahuan tentang komponen - komponen elektronik yang yang dibuat/tersedia di pasaran. komponen elektronik dirangkai agar menjadi suatu sistem/peralatan elektronik yang berfungsi untuk mengendalikan elektron-elektron dari sumber elektron agar dapat bekerja seusai rancangan rangkaian yang diinginkan (Kho, 2020). 
Mempelajari elektronika (tingkat dasar) tidak sesulit yang dibayangkan, hanya butuh kemauan dan memperbanyak kegiatan praktek membuat berbagai sistem rangkaian elektronika sederhana. Namun demikian sebagian orang termasuk siswa/i SMA di Kalimantan Barat merasa kurang tertarik mempelajari elektronika karena mendapatkan informasi tentang kesulitan mempelajari bidang elektronika.

Perkembangan elektronika telah merambah keberbagai bidang seperti industri, perbankan, militer, ekonomi, sosial budaya dan tidak terkecuali juga bidang pendidikan. Beragam media dan alat-alat belajar canggih yang didesain sedemikian rupa membuat dunia pendidikan mampu beradaptasi dengan kemajuan tersebut. Salah satu bentuknya adalah penggunaan media pembelajaran untuk membantu aktivitas proses pembelajaran bagi siswa sekolah (Munadi, 2008). Bambang Warsita (2008: 125) mengungkapkan dalam bukunya "Teknologi pembelajaran : landasan dan aplikasinya" menyatakan bahwa media pembelajaran diartikan "sebagai alat komunikasi yang membawa dari sumber ke penerima". Dua pernyataan ini mengandung arti bahwa media pembelajaran akan membawa pengaruh baik terhadap pemahaman siswa dalam menerima materi belajar. Beberapa penelitian yang berkaitan media media pembelaran bidang elektronika sudah dilaksanakan diberbagai kalangan pendidik. Gede Puja Dewantara, I Gende Ratnaya, dan Agus Adiarta telah merealisasikan media trainer elektronika dasar untuk siswa SMK(2020). Chandra Ainur Rizki (2015) telah menerapkan modul elektronika untuk mempelajari materi dasar-dasar elektronika pada SMKN 2 bangkalan. Hasil penerapan modul elektronika tersebut telah memberi kemudahan bagi siswa dalam memahami matarei ajar bidang daar-dasar elektronika. Richard Tamarugi, Nontje Sangi, Moudi Kambey (2021) menyatakan bahwa metode pembelajaran berbasis demonstrasi telah berhasil meningkatkan hasil belajar siswa SMK pada materi ajar elektronika dasar.

Selama ini bidang elektronika di sekolah menengah atas tidak dibahas lebih mendalam, hanya berupa pengenalan singkat serta diajarkan dengan metode satu arah. Tentunya informasi elektronika sangat sedikit sekali yang diperoleh oleh siswa. Hal ini berdampak pada minat para siswa/i untuk memilih Jurusan Teknik elektro rendah sekitar 3:1 (Borang Elektro tahun 2020). Untuk itu Tim Pengabdian Kepada Masyarakat (PKM) Fakultas Teknik Untan mencoba memberikan materi dan pelatihan elektronika kepada siswa/i sekolah menengah atas di wilayah Kalimantan barat. Kebaruan yang dilakukan pada kegiatan pengabdian ini adalah sistem pembelajaran yang interaktif dengan menggunakan modul pembelajaran yang telah dibuat. Modul pembelajaran berupa kit elektronika yang mudah dan sederhana agar para siswa dapat secara langsung dan mandiri mencoba berbagai macam rangkaian elektronika.

\section{Metodologi}

Untuk mencapai tujuan diatas maka bentuk kegiatan PKM melalui metode ceramah, diskusi, dan pelatihan/praktek terhadap modul elektronika kepada para siswa/i sekolah, dimana setiap siswa dilibatkan dalam mencoba modul tersebut. Kegiatan ceramah dan diskusi akan di sampaikan dari para dosen yang tergabung dalam tim PKM sedangkan kegiatan praktek/percobaan Modul Elektronika dipandu oleh para mahasiswa. Bagian terakhir dari kegiatan ini adalah evaluasi pemahaman materi elektronika dengan melibatkan para siswa untuk merakit rangkaian elektronika sederhana.

Kegiatan pengabdian kepada masyarakat kali ini akan melibatkan 5 orang dosen (Panduan PKM Fak. Teknik Untan 2021), 1 orang Pranata Laboratorium Pendidikan (PLP) dan 2 orang mahasiswa yang turun langsung ke sekolah yang menjadi target dan sasaran PKM. Setiap dosen akan disediakan waktu sekitar 10-15 menit untuk menyampaikan materi 
yang telah dipersiapkan. Kegiatan berupa pelatihan tentang pengenalan tentang elektronika, rangkaian elektronika serta komponen yang digunakan. Penyampaian materi dilakukan selama 30 menit dan kemudian dilanjutkan dengan uji coba modul elektronika serta Praktek merangkaian rangkaian elektronik yang dipandu langsung oleh Tim PKM. Untuk memberi semangat dan motivasi terhadap kegiatan pelatihan Kit IoT, tim PKM akan memberikan souvenir menarik kepada siswa/i yang ikut praktek menggunakan Modul elektronik.

\subsection{Tahapan Kegiatan PKM}

\subsubsection{Tahap Perencanaan}

Tahap perencanaan adalah menentukan sekolah-sekolah yang akan menjadi lokasi pelatihan bagi siswa/i. Ada beberapa sekolah yang akan direncanakan untuk lokasi kegiatan PKM yang berada di wilayah kabupaten Sambas, Mempawah dan Landak. Pada tahap ini tim PKM melakukan kontak secara informal kepada pihak sekolah untuk meminta persetujuan lokasi pelatihan elektronika. Setelah mendapat persetujuan Tim PKM mengirimkan surat pengantar perrmohonan pelaksanaan kegiatan Pelatihan kepada pihak sekolah menengah atas atau sekolah kejuruan.

\subsubsection{Persiapan}

Sebelum kegiatan Pengabdian kepada masyarakat dilaksanakan akan dilakukan beberapa persiapan sebagai berikut :

1) Pembuatan perangkat keras modul elektronika.

Pembuatan Modul elektronika dimaksudkan untuk memberikan kemudahan kepada para siswa dalam memahami elektronika serta penerapannya dalam kehidupan sehari-hari.

2) Melakukan Koordinasi dengan Tim PKM.

Kegiatan ini bertujuan untuk menentukan peran kepada setiap Tim, baik tim dosen maupun tim pendukung (mahasiswa dan PLP).

3) Melakukan orientasi lapangan dan koordinasi dengan pihak sekolah untuk penentuan waktu pelaksanaan, durasi kegiatan, peralatan/bahan yang harus disiapkan oleh pihak sekolah serta jumlah siswa yang akan dihadirkan.

\subsubsection{Pelaksanaan Kegiatan}

Adapun kegiatan PKM akan dilaksanakan selama satu hari mulai dari jam 08.00 hingga jam 12.00. Kegiatan akan dibagi menjadi 2 tahap, dimana tahap 1 adalah penyampaian beberapa materi PKM dari Tim dosen, setiap dosen akan diberi waktu penyampaian maksimla 15 menit. Tahap kedua adalah pengenalan Elektronika dan praktek pembuatan rangkaian elektronika sederhana yang akan dipandu oleh 2 orang mahasiswa.

\begin{tabular}{|c|c|l|l|}
\hline No. & Pukul & \multicolumn{1}{|c|}{ Materi } & \multicolumn{1}{|c|}{ Penanggung Jawab } \\
\hline 1 & $08.00-08.15$ & Pembukaan/pengantar & Pihak Sekolah \\
\hline 2 & $08.15-09.00$ & Pengenalan profile Institusi & Tim PKM Fak. Teknik Untan \\
\hline 3 & $09.00-10.00$ & Pengenalan Elektronika Dasar & Tim PKM \\
\hline 4 & $10.00-12.00$ & $\begin{array}{l}\text { Praktek pembuatan rangkaian } \\
\text { elektronika }\end{array}$ & Mahasiswa \\
\hline 5 & $12.00-12.00$ & Serah terima Modul & Tim PKM ke pihak sekolah \\
\hline 6 & $12.15-12.30$ & Penutupan & Pihak sekolah \\
\hline
\end{tabular}




\section{Hasil dan Pembahasan}

\subsection{Tahap perencanaan}

Pada tahap perencanaan tim PKM telah berhasil menghubungi enam sekolah dan mendapatkan persetujuan untuk pelaksanaan kegiatan pelatihan elektronika dasar. Ke enam sekolah tersebut adalah Madrasah Aliyah Negeri (MAN) Insan Cendikia Sambas, Sekolah Menengah Kejuruan Negeri (SMKN) 1 Sambas, Sekolah Menengah Atas Negeri (SMAN) 1 Siantan Mempawah, SMAN 2 Paloh Sambas, SMKN 1 Mandor dan SMAN 1 Mempawah.

\subsection{Tahap Persiapan}

Pada tahap persiapan meliputi beberapa kegiatan yaitu:

1. Pembuatan modul elektronika dan buku panduan penggunaan modul.

Modul Elektronika terdiri dari 4 bagian,yaitu rangkaian power suply, breadboard, komponen masukan dan komponen keluaran yang dikemas dalam satu tempat/wadah/kotak, sehingga mudah untuk dibawa kemana-mana. Ada dua jenis modul elektronika yang dibuat, namun memiliki fungsi yang sama, yaitu untuk memberi kemudahan kepada siswa/i memahami elektronika dasar. Gambar 1. Memperlihatkan hasil modul elektronik yang dibuat. Selanjutnya pembuatan buku panduan penggunaan modul elektronik, buku ini berisi petunjuk penggunaan dan disertakan juga beberapa rangkaian sederhana seperti diperlihatkan pada gambar 2 .

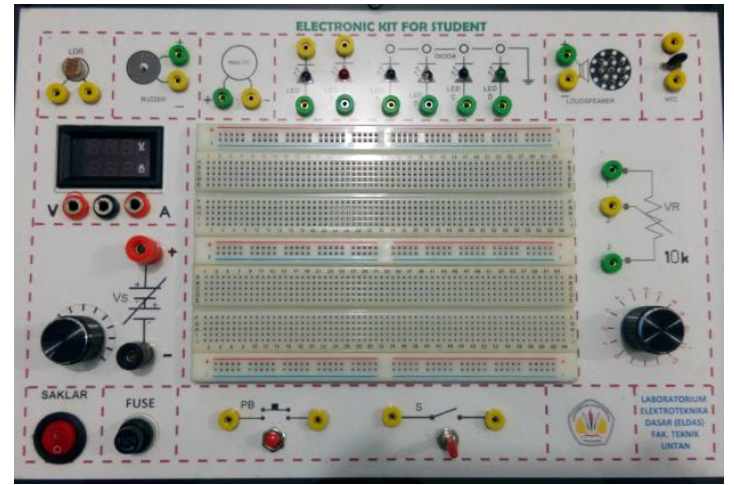

(a)

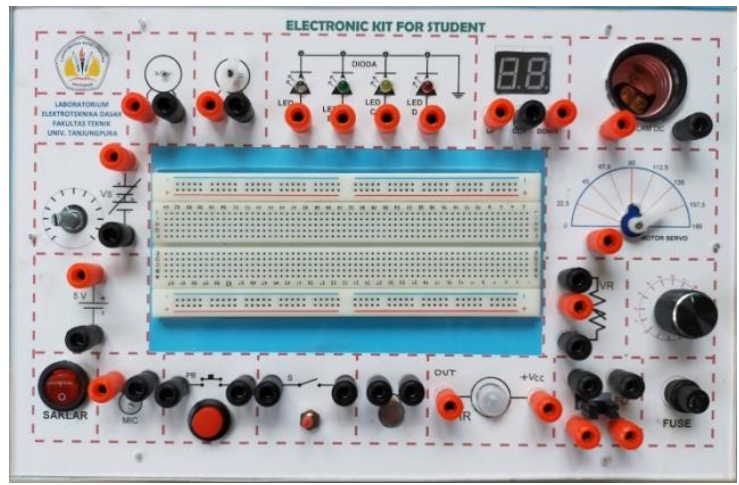

(b)

Gambar 1. Modul elektronik

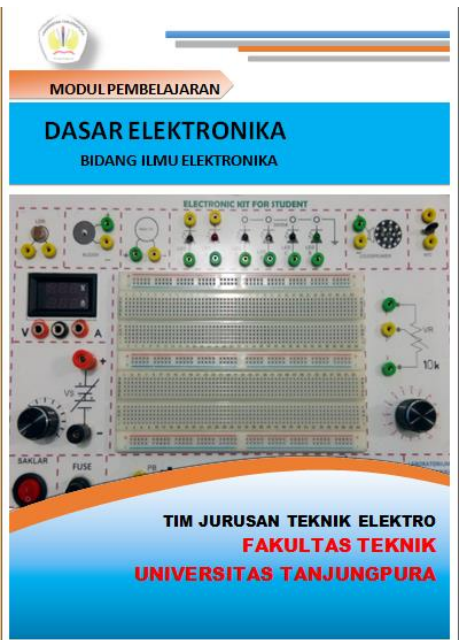

(a) Tampilan Cover Modul

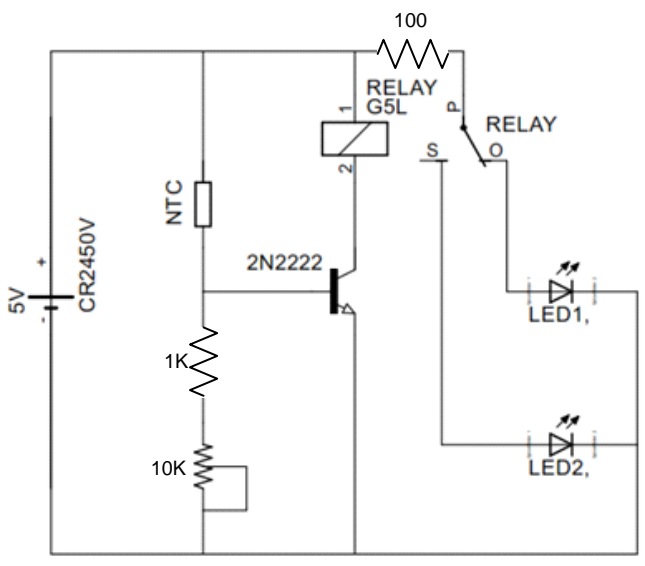

Rangkaian deteksi panas

(b) Salah satu contoh rangkaian

Gambar 2. Modul pembelajaran 
2. Membagi tugas dan peran kepada setiap dosen dan mahasiswa yang terlibat dalam Tim PKM FakultasTeknik .

Pada kegiatan PKM ini, materi yang disampaikan berupa :

1) Profile Fakultas Teknik dan Jurusan/Prodi T. Elektro Untan

Penyampaian Profile Fakultas dan Jurusan disampaikan oleh Neilcy T. Mooniarsih, ST., MT selaku Wadek 2 Fak. Teknik Untan dan Muhammad Saleh, ST., MT Ketua Pusat penjaminan Mutu Fakultas.dan Dr. Dedy Suryadi, ST., MT selaku ketua program Studi Teknik Elektro.

2) Pemaparan singkat tentang bidang elektronika

Pemaparan sekilas tentang bidang elektronika disampaikan oleh Ayong Hiendro, ST. MT, dan Drs. Ade Elbani, MT.

3) Pengenalan dan uji coba Modul Elektronika

Pengenalan dan tata cara penggunaan modul elektronika disampaikan oleh Syaifurrahman, ST. MT dibantu oleh mahasiswa.

4) Pelatihan penggunaan modul eketronika : pelatihan dan praktek elektronika dibimbing oleh 2 mahasiswa dan Jamhir Islami, ST., MT selaku PLP Laboratoroum Elektroteknik Dasar.

\subsection{Tahap Pelaksanaan}

Kegiatan pelatihan elektronika dasar dilaksanakan selama setangah dari pagi hingga siang hari dengan melibatkan sejumlah siswa/i sekolah. Dari enam sekolah yang telah menyatakan persetujuan hanya 5 sekolah yang telah berhasil dikunjungi, Tiga sekolah dilaksakanakan pada tahun 2019 , satu sekolah dilaksanakan tahun 2020 dan satu sekolah dilaksanakan pada tahun 2021. Sehubungan dengan adanya wabah covid 19 pelaksanaan kegiatan di tahun 2020 dan 2021 jumlah siswa yang dihadirkan hanya sedikit sekitar $10-15$ orang perkegiatan hal ini dikarenakan adanya kebijakan pemerintah yang mengharuskan pihak sekolah untuk bekerja/belajar dari rumah. Tabel 1 memperlihtakan jadwal sekolah

Tabel 1. Pelaksanaan kegiatan pelatihan elektronika

\begin{tabular}{|c|l|c|c|}
\hline No & \multicolumn{1}{|c|}{ Sekolah } & Tanggal Pelaksanaan & Jumlah siswa(orang) \\
\hline 1 & SMAN 1Siantan & Kamis, 25 Juli 2019 & 25 \\
\hline 2 & MAN IC & Jumat, 26 Juli 2019 & 25 \\
\hline 3 & SMKN 1 Sambas & Jumat,26 Juli 2019 & 25 \\
\hline 4 & SMAN 2 Paloh & Rabu, 21 Oktober 2020 & 12 \\
\hline 5 & SMKN 1 Mandor & Senin, 14 Juni 2021 & 10 \\
\hline
\end{tabular}

Pada setiap kegiatan pelatihan elektronika ,Tim PKM selalu diterima baik oleh pihak sekolah sebagai tempat kegiatan pelatihan dilaksanakan. Tim PKM langsung melakukan koordinasi dengan kepala sekolah dan wakil kepala sekolah bidang kurikulum dan kesiswaan untuk mekenisme pelaksanaan pelatihan tersebut. Koordinasi berkaitan dengan perkenalan tim PKM dengan pihak sekolah, persiapan ruangan, peralatan yang digunakan, pelaksanaan protokol kesehatan pada saat terjadi wabah coviud 19 serta jadwal susunan acara kegiatan. Gambar 3 memperlihatkan pertemuan antara Tim PKM dengan Pihak sekolah di SMKN 1 Sambas.

\subsection{Tahap Evaluasi}

Evaluasi pemahaman materi elektronika dilakukan dengan cara menguji kemampuan siswa mengenal beberapa komponen elektronika serta membuat rangkaian elektronika sederhana. 


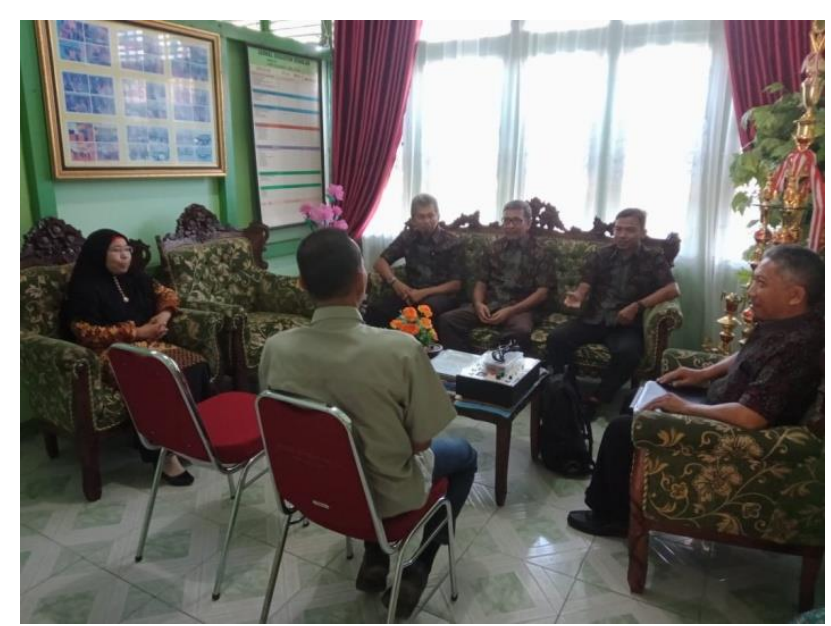

Gambar 3. Koordinasi dengan pihak sekolah SMKN 1 Sambas

Peserta kegiatan terdiri dari para siswa/i dari berbagai jurusan atau wakil dari masingmasing kelas 2 atau 3 siswa yang dipilih oleh pihak sekolah. Untuk kegiatan pelatihan pada tahun 2019 peserta yang dihadir kan sebanyak 25 orang . Namun untuk kegiatan tahun 2020 dan 2021 sehubungan dengan adanya Wabah Covid 19 jumlah siswa yang hadir dibatasi tidak boleh terlalu banyak dan harus menerapkan protokol kesehatan. Gambar 4 menunjukkan salah satu kegiatan pengenalan modul kepada siswa/i SMAN 1 Siantan.

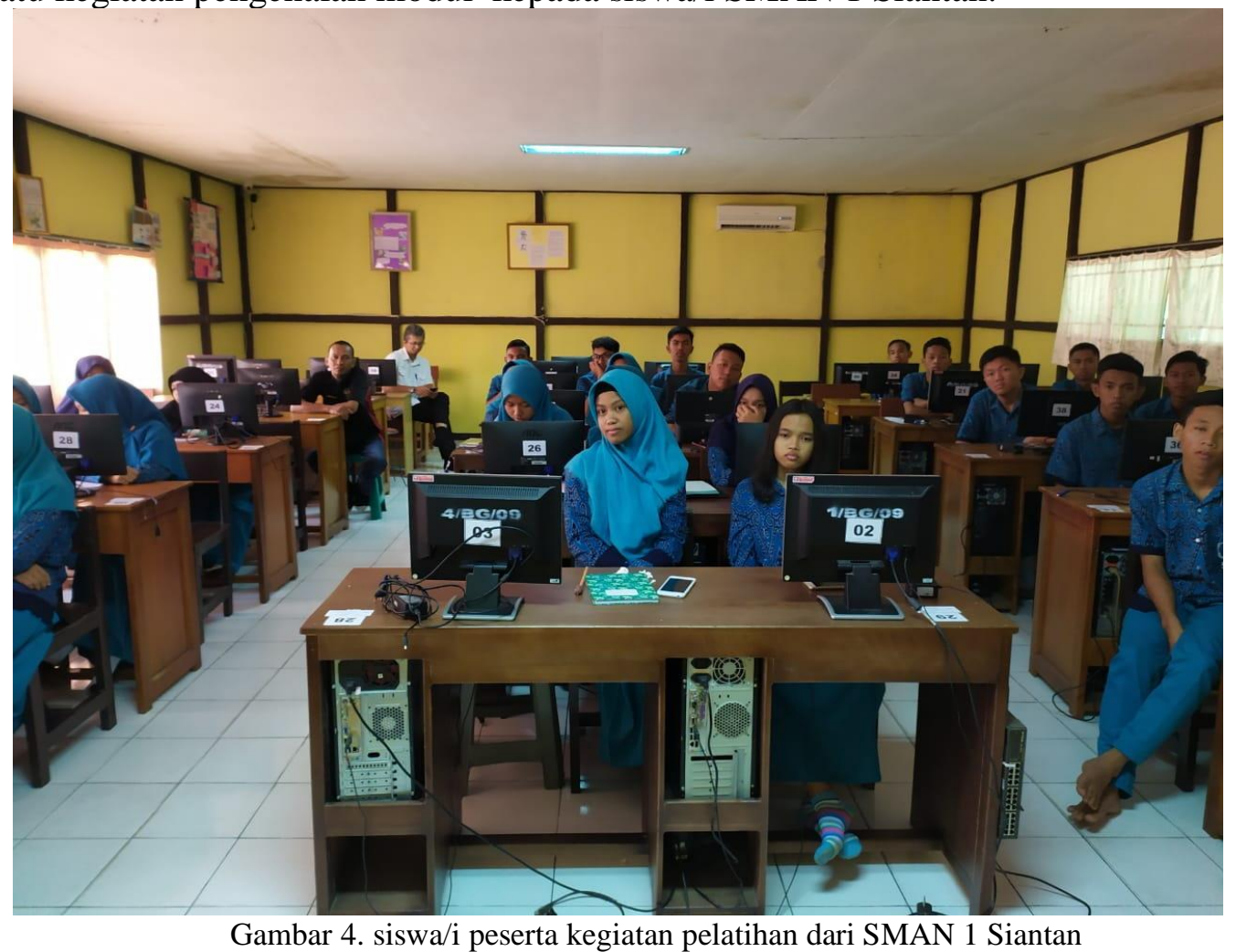

Waktu pelaksanaan ditentukan oleh pihak sekolah berkoordinasi dengan Tim PKM sepanjang tidak mengganggu kegiatan pembelajaran di sekolah tersebut. Kegiatan PKM dimulai sejak pukul 08.00 pagi dan diakhiri sekitar pukul 12.00 siang. Penyampaian Materi diawali dengan pengantar dari Kepala Sekolah atau pihak sekolah yang mewakili. Pihak sekolah umumnya menyampaikan tentang kegiatan pembelajaran di sekolah serta profil singkat singkat tentang sekolah. Selanjutnya perkenalan tim PKM oleh ketua Tim PKM. 


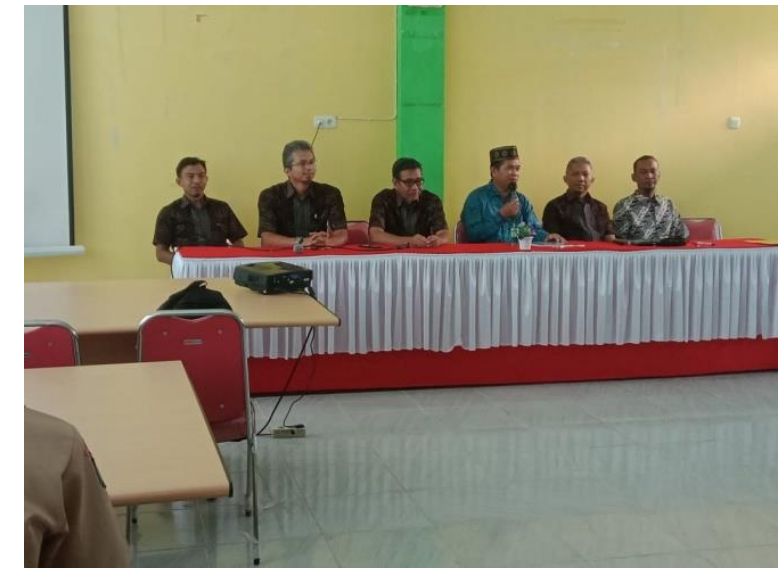

(a)Sambuatan Bapak Mursidin M.Ag kepala sekolah MAN IC

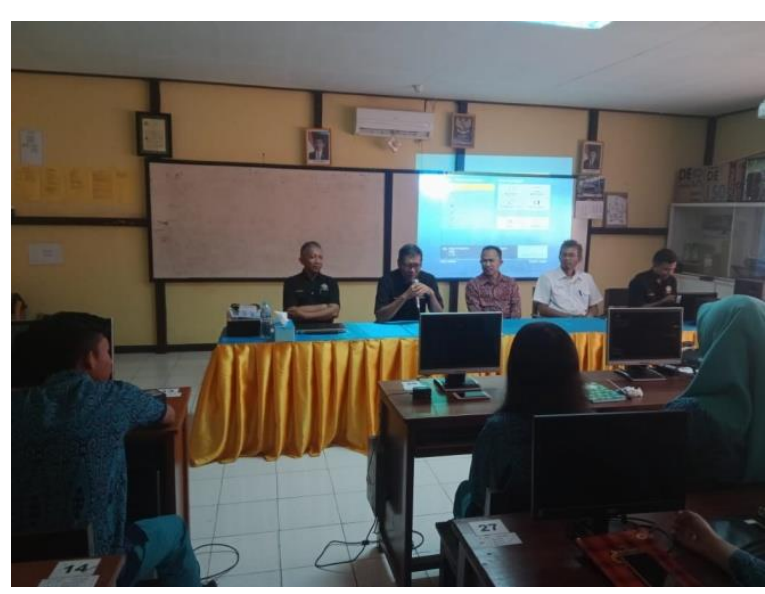

(b)Perkenalan Tim PKM kepada Siswa SMAN 1 Siantan

Gambar 5. Pengarahan dan perkenalan Tim PKM

Gambar 5 memperlihatkan dokumentasi kegiatan pembukaan pelatihan elektronika di sekolah MAN ICSambas dan SMAN 1 Siantan.

Kegiatan selanjutnya penyampaian materi profile singkat Fakultas Teknik Untan dan Penjelasan tentang Modul elektronika oleh Tim PKM. Materi selanjutnya Pelatihan elektronika yang disertai dengan demontrasi /percobaaan modul elektronik oleh 2 orang mahasiswa dan dibantu oleh Pranata Laboratoium Pendidikan (PLP) Jamhir Islami, ST., MT Bagian terakhir dari kegiatan PKM ini adalah demo alat modul elektronik yang telah dibuat sebelumnya oleh Tim Lab. Elektroteknika Dasar. Demo alat dipandu oleh mahasiswa dan Jamhir Islami. yang merangkai beberapa rangkaian elektronika pada modul tersebut. Untuk lebih meningkatkan pemahanan terhadap modul elektronika Tim PKM meminta beberapa siswa/i untuk ikut mencoba merangkai rangkaian elektronik dengan arahan dan bimbingan dari mahasiswa seperti diperlihatkan pada gambar 6 .

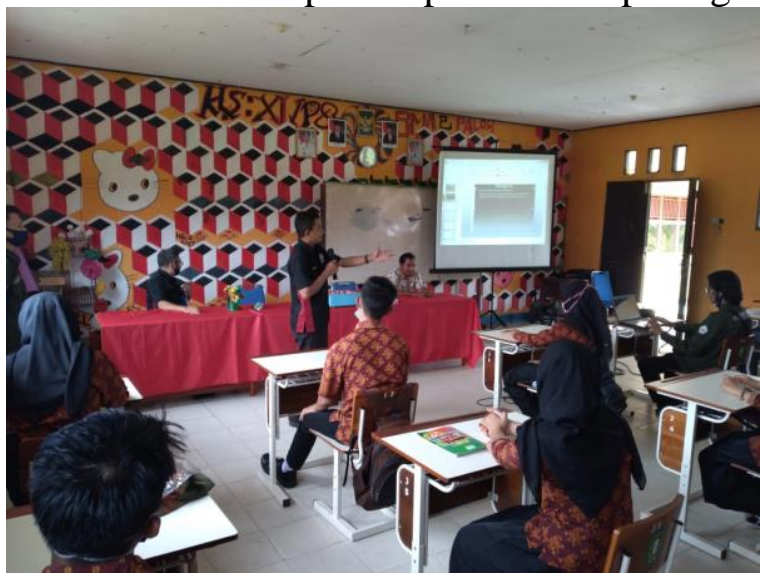

(a)Pengenalan singkat elektronika SMAN 1 Paloh

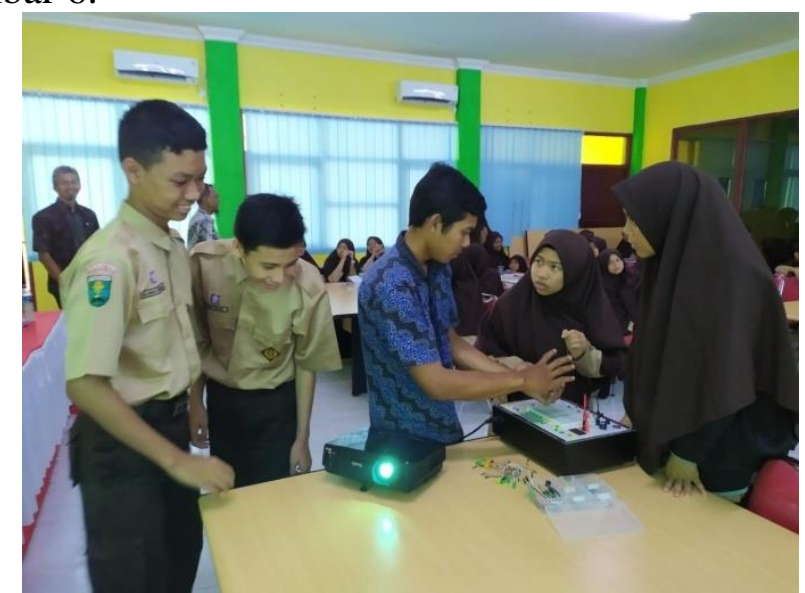

(b) praktek pembuatan rangkaian elektronik MAN IC 


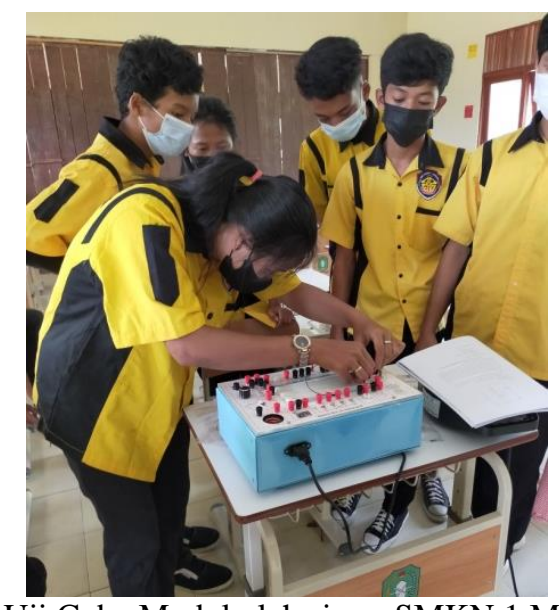

(c) Uji Coba Modul oleh siswa SMKN 1 Mandor

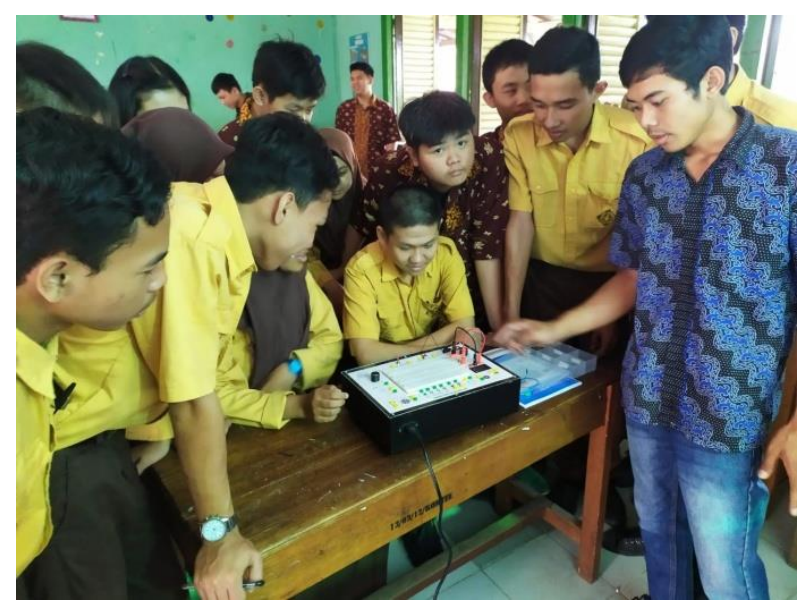

Gambar 6. Suasana pelatihan elektronika

Beberapa hal yang dapat di amati dari kegiatan tersebut adalah sebagai berikut :

1) Tingginya minat dan perhatian para peserta, para siswa yang tertarik pada karya terapan IPTEK serta para guru disekolah terhadap materi-materi yang telah disampaikan pada penyuluhan dan pelatihan singkat, yang ditandai dengan antusiasnya peserta yang mengikuti acara kegiatan pelatihan tersebut.

2) Para siswa-siswi di daerah kabupaten akan lebih banyak mengetahui proses-proses penjenjangan pendidikan tinggi setelah menyelesaikan sekolahnya, serta mengerti tentang kegunaan Laboratorium-laboratorium, kurikulum dan hasil-hasil karya mahasiswa yang ada di Program Studi Teknik Elektro Fakultas Teknik Untan.

3) Dapat memperbesar respon dan minat para siswa-siswi sekolah untuk memilih dan melanjutkan pendidikannya ke perguruan tinggi, baik melalui Seleksi Bersama Masuk Perguruan Tinggi Negeri (SBMPTN) maupun Non UTUL terutama di Program Studi Teknik Elektro Fakultas Teknik Untan.

4) Membantu siswa-siswi untuk mengetahui dengan jelas keahlian-keahlian apa saja yang ada di Program Studi Teknik Elektro Fakultas Teknik Untan.

5) Evaluasi dilaksanakan :

6) Secara langsung pada saat diskusi untuk melihat apakah peserta antusias dalam mendengarkan dan memahami materi yang diberikan pada saat kegiatan berlangsung.

7) Secara tidak langsung, dapat dilihat sejauh mana peningkatan minat dan kualitas lulusan, para siswa-siswi sekolah yang masuk ke Program Studi Teknik Elektro Fakultas Teknik Untan.

\subsection{Penyerahan Modul Elektronik}

Kegiatan PKM Jurusan Teknik Elektro Khususnya Laboratorium Elektroteknika Dasar (Lab. Eldas) Untan diakhiri dengan penyerahan modul elektronik dari pihak Fakultas Teknik Untan kepada pihak sekolah yang diterima langsung oleh Kepala Sekolah atau yang mewakili. Penyerahan modul ini dimaksudkan agar para siswa/i dapat melanjutkan untuk mempelajari beberapa rangkaian elektronik secara mandiri. Pihak sekolah sangat menghargai dan menyampaikan ucapan terimakasih kepadaTim PKM Jurusan Teknik Elektro Fak. Teknik Untan. Gambar 7 memperlihatkan dokumentasi penyerahaan modul elektronik kepada pihak sekolah . 


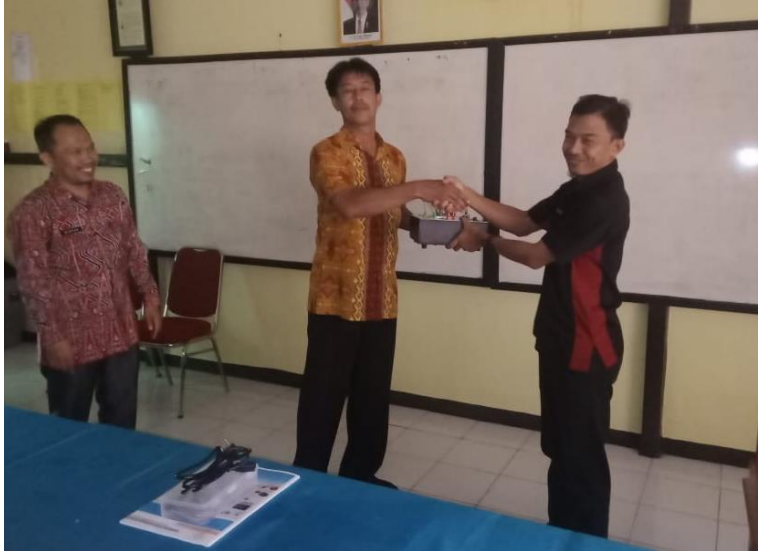

(e)

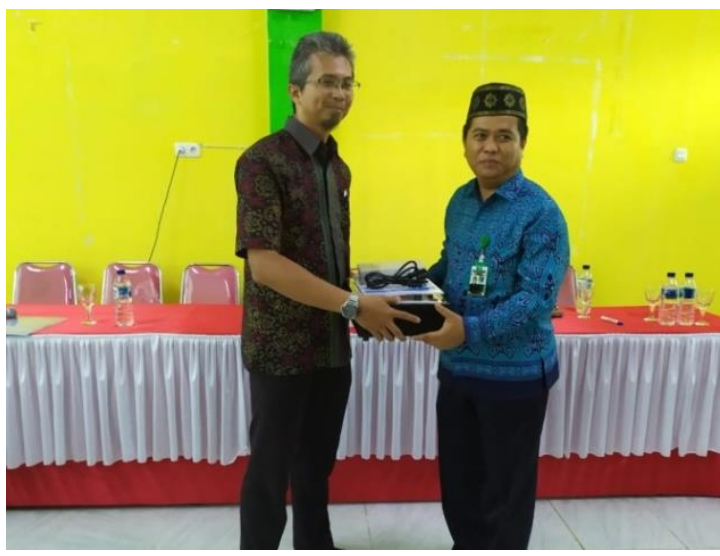

(c)

MAN IC sambas

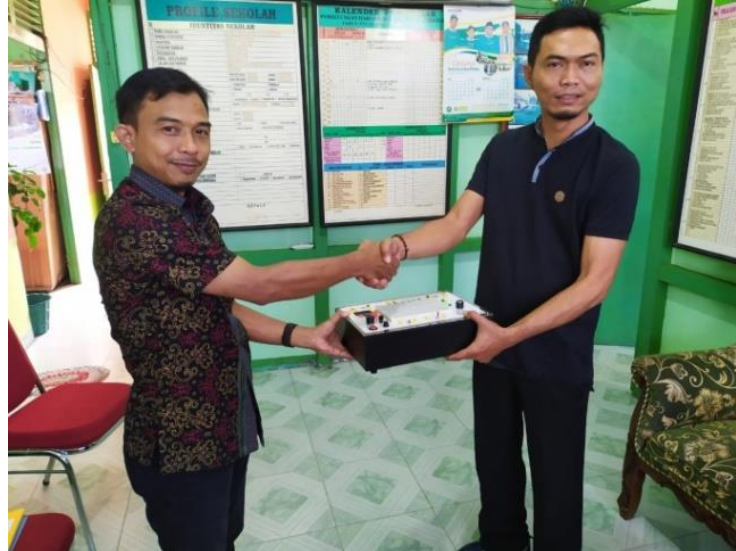

(a) SMKN 1 Sambas

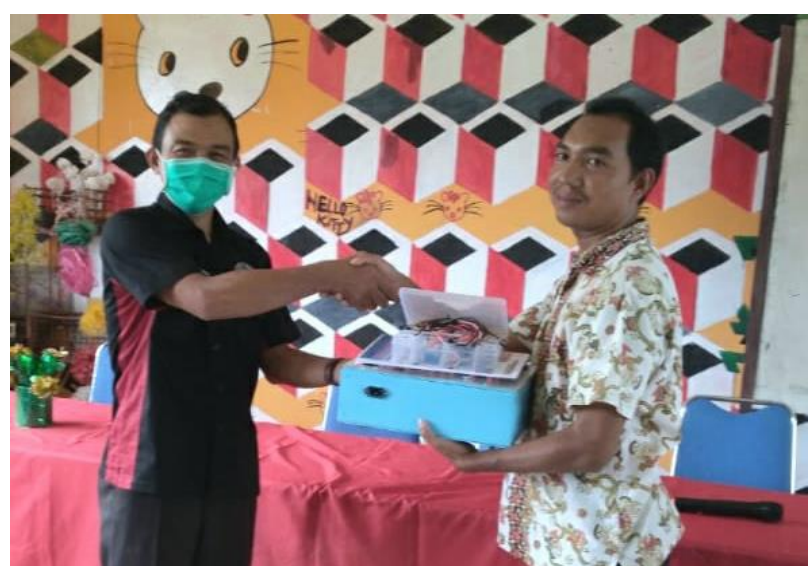

(d)

SMAN 1 Paloh Sambas

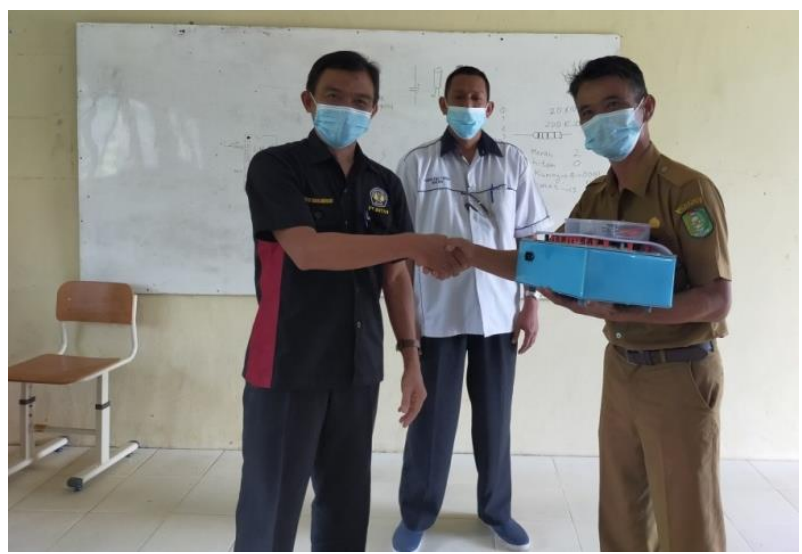

(e) SMKN 1 Mandor Landak

Gambar 7. Serah terima Modul elektronik Kepada Pihak Sekolah

\section{Simpulan}

Dari hasil kegiatan pelatihan Elektronika dan Pengabdian Kepada Masyarakat (PKM) Fakultas Teknik Untan dapat disimpulkan beberapa hal sebagai berikut :

1) Informasi profil Jurusan Teknik Elektro Fakultas Teknik Untan sangat perlu dilakukan agar para siswa/i sekolah menengah atas dapat mengetahui lebih jauh tentang program Studi Teklnik Elektro, khusunya untuk sekolah-sekolah yang wilayahnya jauh dari pusat kota karena dapat membantu siswa/i sekolah tentang keberadaan Program Studi Teknik Elektro Fakultas Teknik Fakultas Teknik Untan. 
2) Selama proses Pelatihan elektronika, minat dan perhatian para siswa terhadap materi kegiatan yang telah disampaikan sangat menyambut baik, yang ditandai dengan adanya pertanyaan yang diajukan serta keinginan mencoba membuat rangkaian elektronik selama kegiatan berlangsung.

3) Kegiatan pelatihan elektronika yang dilakukan dapat memperbesar respon para siswa dan siswi di untuk melanjutkan studinya ke perguruan tinggi, terutama di Jurusan Teknik Elektro Fakultas Teknik Untan.

4) Para siswa telah memahami materi elektronika dasar, hal ini ditunjukkan dengan keberhasilan dalam membuat/merangkai berbagai macam rangkaian elektronik.

\section{Ucapan Terima Kasih}

Ucapan terimakasih disampaikan kepada Fakultas Teknik Universitas Tanjungpura yang telah membiayai kegiatan Pengabdian Pada Masyarakat sehingga kegiatan pelatihan elektronika kepada siswa/i di wilayah kabupaten Kalimantan Barat dapat dilaksanakan dengan baik. Terimakasih juga kami sampaikan kepada seluruh pihak sekolah yang telah menerima kami dengan setulus hati demi kelancaran kegiatan ini.

\section{Daftar Pustaka}

Dickson Kho,Pengertian Elektronika, Artikel, https://teknikelektronika.com/pengertianelektronika-electronics-definisi-elektronika/, diakses tanggal 2 Juli 2020

Yudhi Munadi, 2008, Media Pembelajaran, sebuah Pendekatan Baru, referensi GP Press Group.

Bambang Warsita, Teknologi pembelajaran : landasan dan aplikasinya, Penerbit Rineka Cipta , Jakarta, 2008.

Gede Puja Dewantara, I Gende Ratnaya, dan Agus Adiarta, Pengembangan media Pembelajaran Trainer Elektronaika Dasar untuk Siswa SMK, Jurnal Pendidikan Teknik Elektro Undhiksa Vol. 9 No. 3, 2020.

Chandra Ainur Rizki, Pengembangan Modul Elektronika Dasar Pada Kompetensi Dasar Menerapkan Dasar-Dasar Elektronika Terhadap Siswa Di Smk Negeri 2 Bangkalan, Jurnal Pendidikan teknik Elektro UNS, Volume 4 No. 2, 2015

Richard Tamarugi, Nontje Sangi, Moudi Kambey, Penerapan Metode Pembelajaran Demonstrasi untuk Meningkatkan Hasil Belajar Elektronika Dasar, Jurnal Edunitro Univ. Negeri Manado, Vol.1 No. 1, april 2021.

Tim Revisi panduan PKM Fakultas Teknik Untan, Buku Panduan PKM Dipa Fakultas Teknik, tahun 2021.

Tim akreditasi Prodi Elektro, Laporan Borang akredtiasi Prodi Teknik Elektro Untan, tahun 2020.

Malvino, Prinsip-Prinsip Elektronika Jilid 1, Penerbit Erlangga, 1994

Elektur, 273 Rangkaian Elektronika, Elek Media Komputindo, Jakarta, 1994

Fakultas Teknik Universitas Tanjungpura (2018), Buku Pedoman S-1 Fakultas Teknik Universitas Tanjungpura, Kalangan Terbatas. 